Portland State University

PDXScholar

$11-4-2017$

\title{
Social Class and the Establishment of the London Metropolitan Police Force
}

Michelle C. Zachary

Portland State University

Follow this and additional works at: https://pdxscholar.library.pdx.edu/honorstheses

Let us know how access to this document benefits you.

\section{Recommended Citation}

Zachary, Michelle C., "Social Class and the Establishment of the London Metropolitan Police Force" (2017). University Honors Theses. Paper 498.

https://doi.org/10.15760/honors.501

This Thesis is brought to you for free and open access. It has been accepted for inclusion in University Honors Theses by an authorized administrator of PDXScholar. Please contact us if we can make this document more accessible: pdxscholar@pdx.edu. 
Social Class and the Establishment of the London Metropolitan Police Force by

Michelle Zachary

An undergraduate honors thesis submitted in partial fulfillment of the

requirements for the degree of

Bachelor of Arts

in

University Honors

and

Criminology and Criminal Justice

Thesis Adviser

Brian Renauer 


\section{Abstract}

\section{Introduction}

Crime is seen as an undisputed aspect of our culture in both modern day and through much of our history. We have thus adopted multi-faceted and ever-changing methods for controlling this phenomenon and have relentlessly sought a solution for this persevering trait, seemingly inextricable from the development of mankind. It is also inarguable that different aspects of human culture and society have progressed simultaneously and not altogether separately. Each facet of our advancement as a species has influenced how we see criminality and criminal behavior and, consequently, our reaction, as a social species to this circumstance. We are also constantly dealing with the issue of inequality between members of society. As a general and possibly oversimplified definition, we refer to one of these categorical inequalities in terms of social class. Class distinction has historically come into play when we study crime but not so much when we examine the social reaction to crime. If humanity is indeed constantly affected by both crime and class designations, it follows that any solution to crime could also be rooted in these two aspects of historical and modern life.

This analysis focuses specifically on the effects of interactions between two aspects of human society; crime control and class structure in the mid to early 1800's in London, England. The reasoning behind this decision lies in the concept that what we now consider the modern basis for crime control was developed during this period and in this specific location; a debate within itself. The goal of this thesis is to examine how much of an influence, if any, class-based 
social structure had on the creation of what we now consider our modern methods of crime control. To this effect, the social atmosphere and class distinctions in nineteenth century London, England has been investigated in relation to the establishment of the London Metropolitan Police Force, which is often considered to be the basis of modern crime regulation. In conducting this analysis, a premise may be devised as to how established social structures impact the societal reactions to crime and deviance. In obtaining an understanding of the developmental connections between class and crime control, we can gain a more rounded understanding of the modern inequalities, influences, and methods of crime control.

As new and developing social strategies of crime control are not independent aspects of society, especially when related to the social structures, they cannot be analyzed as such. Multiple other factors of human culture and civilization must also be acknowledged, such as advancements in technology and shifting networks of economic power. Resources for this study have therefore been drawn from diverse disciplinary fields such as sociology, psychology, history, and criminology and been scrutinized with the goal of understanding the specific significance of the interplay between class structure and historical methods of crime control in London.

Research on the subject for the purposes of this analysis reveals a high level of intersectionality between class structure and the development of what we consider the modern police. The questions under scrutiny are how and why. For example, did the class system itself directly lead to the establishment of what we consider the modern police? Perhaps it was the establishment of social control which preceded notions of class. We must also consider the possibility that class and early policing historically play off each other to the point where they cannot be separated. It seems an accepted fact within the discourse that the London Metropolitan 
Police and the class-based system of England interacted to shape the modern world of crime control but the aim of this research is to understand how that interaction influenced the history of crime and policing. This research will also examine whether or not the reciprocity of class systems and modern policing was inevitable in the historical evolution of social control methods.

\section{Two Perspectives: Conflict and Consensus}

Within the discourse there are two main theories which can be used to examine the role of class in the establishment of the modern police in London; the conflict perspective and the consensus perspective. These concepts have been used to examine sociological phenomenon since Émile Durkheim helped establish the field of sociology. The consensus perspective can be traced back to Durkheim's concepts of social solidarity, specifically 'organic solidarity', which refers to the collective goals that a society shares regardless of social standing (Durkheim, 1893). On the contrary, the conflict perspective originated in the concepts of sociology related by Karl Marx. Marx suggested, in his discussion of the bourgeoise and the proletariat class divisions, that societies with such class-defined disparities of labor and wealth will create natural conflicts of interest when it comes to social policy (Marx and Engels, 1848). He also implies that this class conflict can result in a false consensus or one that is seen as agreed upon by all members of society but is established and controlled exclusively by the upper class. Using these two perspectives we can determine what role class played in the creation of what we consider the modern police, as both the concept of class and the tangible controlling force of police are products of society.

\section{Defining Class}


One of the problems argued in the discourse Police In the Class Structure, is that class itself remains unexplained and without a stagnant definition (Reiner,1978) This author states that class as a term has been used to describe aspects of life and society everywhere from social status to economic strata, with some definitions remaining entirely purist while others combine aspects to form meaning. Many authors will specifically identify their definition of class in relation to their argument, making class itself a topic of debate. If, as a discourse community, class itself is not a solid topic, then how can we begin to understand class as a governing factor for social change?

For the sake of understanding class in relation to the factors influencing London at the time of the industrial revolution and the creation of the London Metropolitan Police, I will focus on a view of class presented by Michael W. Kraus, Paul K. Riff, and Dacher Keltner (2011). In this context the most basic identifiable factors of class are "Observable symbols of wealth, education, and occupation..." (Kraus et al., 2011). Therefore, we accept that those people with the most wealth, the highest level of education, and the most socially-accepted occupation, providing a steady level of income, are in the highest class bracket.

\section{Evolution of Class Structure In Society: Kinship to Class-Based}

In order to gain a viable understanding of how a relationship between class structure and the organized modern police force could have evolved, it is necessary to understand how and why society in England became ruled by a stratified, class-based culture. According to the discourse The Origin and Evolution of the Police Function In Society, England and the rest of the 'modern' world has developed from a kin-based to class-based society over the last few centuries. (Robinson and Scaglion,1987) These authors describe kin-based societies as those which are self-sustaining and mostly isolated. It is their assertion that the transition to a class-based society, 
in other words, one which is ruled by a state, or a centralized, government, is marked by the kinship-based society's ability to begin producing a surplus of resources. Once this occurs, competition for resources takes place and there is suddenly a struggle for control over those resources. It is at this point in the evolution of societies that a class-based structure begins to form.

Continuing on this line of reasoning, Robinson and Scaglion argue that the basis for class structure in society develops as a result of unequal divisions of labor due to a surplus of resources by a particular group. The group possessing more of the surplus resources eventually transitions into the upper class, as they use their excess resources to dictate the division of labor, making more prominent the division between emerging classes. These authors state that this transition occurs once a society begins producing beyond their need. When a community's only production is of the food they then consume, a system like class structure would be impossible to maintain. However, once enough surplus food or other materials are produced, a profit is possible, providing the basis for class division.

For example, when a kin-based society devises the means to produce a surplus of a product, say, tools, there eventually becomes a time where every member of the community need not work to sustain a steady supply of tools to sell and use. As a result, a group within society breaks off, sometimes under the pretense of overseeing the workload, and subsequently exists as members of the community while no longer contributing to its sustainability. Often, this group will take on elevated or ceremonial roles within society, such as spiritual advisors, and become set apart as a necessity of society. As a result they are in a position to influence labor and production and to claim the benefits of the sale of the surplus for themselves. Robinson and 
Scaglion call this division of labor and profit complex redistribution and cite its development as the basis for class divide.

These authors further assert that the emergence of a class system promotes the shift to a state-based government, in other words, one that maintains centralized control over the resources of the whole society, and that this occurs because of the inability of a kinship-based structure to maintain a class divide. Once the rift between these newly formed classes grows, there occurs a fundamental social shift in the layout and functioning of society. Therefore, we can assert that distinct classes emerged, progressed along with, and ultimately led to, the development of a government structure based on the existing class brackets.

\section{Arguments Over Class Structure and Police Origins}

It is important to establish, in the case of policing and its origins, if the discourse promotes a situation where conflict and consensus perspectives are set against each other or if there is an agreement that they are both present but played different roles. Within the discussion of conflict perspective, the emerging question is whether such societal changes which prompted the creation of the new police were enacted with conscious intent beyond simply peacekeeping. For consensus perspective the matter becomes the intent and objectives of different classes in the creation of the police.

The Origin and Evolution of the Police Function In Society relates the theory that policing, as an institution, did not develop separate from social factors. In fact, Robinson and Scaglion claim that the underlying reason for the development of a synthesized police force came directly out of England's transition from a kinship-based to a unified governmental structure, using the concept of class stratification as a bridging factor. Out of that new unified government 
and further ingrained class division comes the need for enforcement of the status quo. Those who've found themselves in the upper classes of society now seek to maintain that authority through enforcement. When the transition occurs, those with the most power seek to maintain control of the surplus resources, therefore, they seek to establish a force to assert their control. In state-based societies this takes the form of a government-controlled system which aims to perpetuate the current power base. Organizations like the police are a perfect example of this system at work. Their job, if we accept this definition of societal transition, is to retain control for the upper classes while ensuring control over the lower classes; in the case of London, the emerging working class during the industrial revolution is an example. It can therefore be asserted that the establishment of modern policing in inextricable from the development of a class-based structure in society.

Robinson and Scaglion are not the only ones producing research suggesting that a specific social structure is necessary for the emergence of enforcers of that system. Robert Reiner suggests, in his discourse, Police Research in the United Kingdom: A Critical Review, that the London Metropolitan police as an institution was, at the basest level, answerable to the stratified structure of the society that created it. He submits that "It's foundation was a hierarchical and deferential social order...hidden because of the deference to authority maintained in a rigidly class-stratified society." (Reiner, 1992). This ideology would assert that the police in London could not have emerged in their recognizable form without the, perhaps unconscious, support of the dominating social systems at the time.

While it is entirely possible that the upper classes consciously sought a means to retain social control, this explanation also makes it seem possible that modern social control systems formed unconsciously as a means of control which integrated itself into the new and changing 
social systems. When urban population rose drastically during the industrial revolution, older systems of crime control became less effective in suppressing crime (Lyman, 1964). By this token, both the conflict and consensus perspectives would have merit when contemplating motivations for social control methods. Once class has been formally established, it becomes expected and seen as essential to the functioning of 'civilized society', therefore, even those in the lower classes are aiding the persistence of a stratified social structure. The London Metropolitan Police were comprised of members of the lower class but controlled by those of the upper class.

There also exists the argument that the class-based system was necessary to the creation of the modern police based on the concepts of leisure and livelihood. While the working class found it necessary to work long and grueling hours to maintain a livable space in English society, they were also vital to the class system as they created the productivity and the surplus necessary to maintain an upper class. Members of the exclusive upper class did not only have a greater amount of wealth and status-based power but were also proponents and consumers of free time. Although members of the upper class did hold vital government positions, they did not maintain the long hours of the working class and did not have to rely on income from employment. Thorstein Veblen coined the term 'leisure class' to describe those members of society who had the means to consume time in a manner that was not productive to the function of society. In London during the nineteenth century, these upper-class individuals have the same role as the ceremonial leaders during the transition from a kin-based system.

It was this surplus of time created by the class-based social system that allowed the possibility of a system like the modern police to be established. For example, while the lower classes needed to maintain production for the successful maintenance of society and their own survival, the upper class had the time to create separate and elaborate social systems like the 
police. Social control is an unavoidable aspect of society and the established social structures of class in London provided the blueprint for the type of social control the society could create and maintain. This leisure class provided the techniques with which to implement them for the good of their society.

\section{Conflict Perspective of Police Origins: Class as A Reason}

Conflict perspective has come to be defined within the discourse as a system in which there is "...an uneven distribution of self-interests in crime control and an uneven distribution of power to implement self-interests into social policy" (Liska, 1987). The basis for argument when it comes to the relationship between class systems and the police is that this uneven power distribution created a system of exploitation through upper class control. If we use this perspective to examine the establishment of the modern police, we assume the English aristocracy both conceptualized and founded the new police with the motive not of peacekeeping but of malignant social control. This assumed desire for supremacy over the lower classes was not the only societal factor which led to the policing establishment but it is the motivating factor driving the conflict perspective in association with class divides when we examine the process of social change present at this time.

\section{J. V. Jones, author of The New Police: Crime and People In England and Wales} emphasizes the fact that the development of the modern police was a process over time and not a single overhaul of an older and now ineffective system (Jones, 1983). This discourse promotes the idea that the London Metropolitan Police formed due to the general impression that crime and disorder were on the rise during the industrial revolution, due to the influx of people into London. While this increase was a factor, it was not the primary drive behind the creation of the new police, Jones maintains, and goes so far as to argue that historians in general have been 
negligent in their investigation into alternative factors behind the formation of the London police force. It is possible that the fear of rising social disorder was mass produced by the upper classes looking to maintain social control through executive order. Jones explains that there was a clear perception of the lower class as a threat to the existing social order and it is possible that this fear was the true driving force behind the establishment of an organized police force in London.

It is a fairly common thread of research that some kind of societal transition was the structural basis which caused the need for the establishment of a synthesized police force. There is also not much dissent for the idea that class was a determining factor in that transition but the question remains as to when in history the defining transition occurred and the nature of the shift. For example, Dickson and Speirs in their discourse, Changes in Class Structure in Paisley, 17501845, claim it was during the beginning of the industrial revolution, around 1750, that class structure in England began to develop from one based on an agrarian society to one based in industry (Dickson and Spiers, 1980). As such, new social classes began to emerge as they related to standing in this new age. Again, this is a transition based on the utilization and control of resources but it differs in the point at which class conflict developed in society to make way for the formation of a specific control structure.

Another discourse which points to the changes in industry in the late 1700's and early 1800 's as a factor is that of J.L. Lyman. According to this author, the previous systems of class and social control became ineffective once the urban population in London began to grow (Lyman, 1964). A system once maintained through community-based efforts was now unable to meet the demands created by this dramatic shift. There were too many people and a newly developed working class was ushered in by the industrial revolution which needed a new system of social control to regulate. These changes to the social norms of the time inspired fear in the 
upper classes, as they were concerned that their place in the social system could be compromised. As a result, a system of control in the form of the London Metropolitan Police began to form.

It follows that there are two crucial shifts in society leading to the establishment of the Metropolitan Police in London and with a basis supporting the conflict perspective. The first occurred when society adapted from one that was controlled through local systems and maintained by an integrated, community-based system of control to one that relied on the direction of a ruling class. It was in this transition that distinct classes first developed, using the production and control of resources to promote certain members of that society to a higher position which they were then able to control and maintain by exercising their influence gained through that standing.

The second developed when England transitioned to industry-based production. During the 1800 's there emerged a new class which detached from the existing working class. This new class, the educated working class, shifted the existing system of class control in a way which was seen as threatening to the upper classes. Therefore, there was a need to establish a control system to maintain the upper class dominance within the social system of London. Out of this need emerged the basis for our modern law enforcement in the form of the London Metropolitan Police Force. Both of these transitions focus on the control of resources, the basic underlying argument being that methods of modern social control developed as a means of controlling these resources. They also rely on the idea that the classes were inherently uneven in the power they had over the direction of society.

There had historically been three class structures identifiable in England for so long as class has played a role in the functioning of society; the aristocracy, the middle class and the 
working class (R. S. Neale, 1968). These classes persisted although they developed more divisions within themselves as class lines began to blur in adjustment to the new functioning of society. R. S. Neale, author of Class and Class-Consciousness in Early Nineteenth-Century England: Three Classes or Five? addresses the issue of looking at class structure as a similar phenomenon before and after the industrial revolution. Neale states that the changes in class structure during the late 1700's and the early 1800's were concentrated on the middle and lower classes, more specifically, the classes whose lives were most directly impacted by the shift towards industry. He asserts that distinct and developed classes are based on particular historical conditions including political climate and economic shifts. Furthermore, "Social classes, however, are really conflict groups arising out of the authority structure of imperatively coordinated associations. Social class defined in this way can be objectively identified, at least in part, by setting out the authority structure of associations" (R.S. Neale, 1968). If it is appropriate for class structures to be determined based on authority in a historical context, and, in turn, to define authority structures, then it is imperative to examine how those structures function within working society and what their formation was based upon. This consideration leads back to the initial proposal of the theory that class developed as a result of resource management.

The aristocracy, rich landowners who conducted trade and economy and are supported by those in the middle and working classes, were the individuals garnering most of the influence in society. This class remained intact during the industrial revolution for the most part however there were new threats by the lower classes to the positions of power due to the shift in the economy. The police, as they emerged, were taken from the ranks of the lower working class, skilled laborers who earned their job positions based on ability considered only slightly above 
manual labor. Police Research In the UK suggests that the newly formed police drew in its ranks due to the promise of job security, rather than a personal desire for law and order (Reiner, 1992).

Here emerges the paradox of police in the class structure. If the police are lower class themselves then they don't benefit from a system enforcing control of labor and resources and designating the rewards to the upper classes. However, if Reiner is correct in saying that early police were simply looking for steady income then the apparatus of the modern police takes an almost sinister role in society, as a system which works against the people in charge of maintaining it. Drawing from Marxist theories about the conflict perspective, it is also possible that this is an example of the false consensus. Whether conscious or not, the upper classes succeeded, in the creation of the London Metropolitan Police, to create a self-sustaining system; the police, a section of the lower class, rely on their jobs to survive and therefore the need for policing is cemented and the upper classes rely on the system to maintain control of the lower classes. Both members of the lower classes and upper classes perpetuate this need for police through the social fear of crime which came with the industrial revolution (Jones, 1983).

Within the discourse on this subject, there is no argument present stating that class was not a defining factor in the way the modern police developed. Up to this point, the history related to the development of police in a changing society is either agreed upon or, at the very least, unchallenged. However, there is a divide when it comes to interpreting the role that class played. Some authors are of the opinion that class itself made the creation of the London police force both necessary and possible while others argue that class itself was not a primary factor but that class control was the means by which societal change was enacted. The way different classes and thus, power structures, were affected is crucial in understanding the social role of police in the historical context of the city of London. At this point it is inarguable that changes in class 
structures during the time the London Metropolitan Police Force was formed played a part in its creation; however, there exists the question of which theory as to the role of class made a more substantial contribution.

\section{Consensus Perspective of Police Origins: Class As A Means}

The consensus perspective is not entirely opposite to the conflict perspective within the discourse. Rather, it is presented on the basis of human rationality; "It assumes that a general consensus exists on goals and values, that general needs for survival can be identified, that social structures (persistent patterns of behavior) function to maintain society's values, goals, and needs, and that social structures can be explained by these functions." (Liska, 1987) Essentially, Liska implies that we will always be drawn to methods of social systems which inherently increase our chances of survival and prosperity. In the case of the emerging police, members of all classes would have benefited from a more effective system of crime control, as the swelling urban population inexorably led to higher crime rates (Edward L. Glaeser and Bruce Sacerdote, 1999).

Author A.L. Dixon focuses on the organization of the modern metropolitan police, including the process of training and selection of officers (Dixon, 1929). Within this article, the section 'Historical Growth and Organization' presents the idea that while the new police were considered modern, social control methods have actually been growing and developing throughout centuries of English history. In this section the author focuses on the modern police system as a mix of central and local powers, citing links to the history of local crime management techniques. Dixon suggests that the movement towards this initial unification into a coordinated law enforcement effort, which had to occur for the London Met to function, was crucial in the history of policing. 
The controversial position of police in the modern system is an area researchers have examined but not in-depth and not in relation to the class system besides an occasional acknowledgement of the connection. Reiner in his article Police In the Class Structure identifies this paradox (Reiner, 1978). He explains that the political leanings of police have historically been both for and against 'the people', meaning their fellow working-class citizens, sometimes favoring the upper-class agenda over their own needs. This incongruity suggests that the connection between police and the class system has a great unseen influence.

Author Gregory Clark also considers the development of class and class structures (Clark, 2005). Here, emphasis is put on pre-industrial revolution and the causes which led to the creation of a new working class. In short, the author pinpoints social factors as the cause, particularly the increase in literacy and education during that period as well as the influx of people into urban areas. At this time the working class had to be divided in two with unskilled laborers and skilled laborers as two classes that had a similar place in society but were diverging in the new age of industry. It was this change in the structure of society that led to the inevitable formation of a new system of social control.

Sir Robert Peel, the main party involved in establishing the London Metropolitan Police, lends himself to the seeming paradox of the police in the class system. He was a member of the upper class in the United Kingdom at the time, even rising to the position of Home Secretary later in life. However, throughout his career he displayed a legitimate desire for fair social order, as is shown through his crime control ideologies or the 'Peelian principles' of policing which call for an unbiased and even-handed approach to social control.

In 1812, Ireland, Robert Peel formed what was known as the Pease Preservation Force in response to uprisings by agrarian laborer's in that region (Broeker, 1961). In this instance, Peel 
not only formed a paramilitary force, not dissimilar to what he later did with the London Metropolitan Police, but also pioneered a system of accountability for the local leaders. Peel reached this compromise by examining the problem and deciding that the best fix would be not only to control the working-class laborer's who were upset with the ruling system but also to determine the reasons for their noncompliance. He determined that by creating a system whereby the upper-class magistrates employed a small group of enforcers for their own security, they could function at their posts without as much fear of the violent uprisings while also acting as supervisors for the state, reporting on whether the magistrates were doing their job. In this example, Sir Robert Peel successfully demonstrated not only his strengths as a policy maker but also as a member of the ruling class who valued the members of every class as valuable members of a civilized and functioning society.

It is crucial to note that Peel used the same principals to build the London Metropolitan Police later in his career. Rajesh Joshi notes, in his discussion of widespread prejudice in the modern police of London, that the London Met were originally founded by Peel with the condition of accountability to the community they served (Joshi, 2000). Even after the London Metropolitan Police were well established as a peacekeeping force in London, Peel continued to consider and revise mandates and propose solutions to unforeseen problems within the force (Lyman, 1964). It is clear from Peel's career-long dedication to the ideals of a fair and just system of social control for all members of society.

If we think of the creation of the London police in 1839 through the lens of social architects such as Secretary Robert Peel, we have to accept that this method of social control was not devised with nefarious purposes on the part of the upper class, but as a force to uphold the rule of state and also the personal rights and safety of citizens. Undeniably, it is true that without 
the structure the upper class provided to the society of $19^{\text {th }}$ century London, such an organized force as the London Metropolitan Police would not have developed. As it was, members of the upper class who were purveyors of social reform were the ones who, historically, led the advancements in policing and law enforcement in general. Henry Fielding, founder of the Bow Street Runners was an English magistrate and although his force was disbanded during the time of the Metropolitan Police Act, his initiatives helped promote the idea of state-funded peacekeeping ( J.M. Beattie, 2007)

Police Control Systems In Britain, 1775-1975, by Chris A. Williams produces examples of both theories of class in relation to the foundation of modern policing (Williams, 2014). For example, he states that the police pre-1829 were partially defined by their lack of centralized authority. In other words, they were not so much an official organization as a number of separate factions. Therefore, the new police, as he terms them, became known as such because of their new reliance on the control of a centralized government. Williams also argues that at this time there was a move towards centralized bureaucracy not just by the national government but by notions of social control methods as well. Consequently, it is possible to claim that, at the time, the police and the government of Britain were moving in the same direction - towards centralized bureaucracy - and therefore their needs were aligned. The police would have needed a recognized authority to provide overreaching reform and regimentation while the government, at the time, saw the need for a method of maintaining a higher standard of public order. It is necessary to point out, then, the difficulty in describing a centralized bureaucratical peacekeeping force without basing it in a system controlled by class or other divisions of power. With the implementation of this new policing system, no matter the possibly hostile upper-class 
intentions behind it, crime would be reduced, a result that would have benefited all members of society.

Williams also describes the new police as a result of attempts to control labor within a class-based society. He explains that the rise of capitalism and the resulting economic competition played a major role in the reformation of policing. Within this structured reform exist two classes, according to Williams: the administrative class, or government-based authority and the executive class, or the laborers. The new police existed as members of the executive class, working to stabilize and regulate the rest of the labor force in order to stimulate the growth of and authority over Britain's economic expansion. It is a common thread within the discourse to have difficulty placing the police into the established class structure of any time period. The London Metropolitan Police, for example, reflected the class systems of the early 1800's in England, meaning the upper class controlled the functions and goals of the newly formed police while the day to day workers were taken from the ranks of the lowest class.

Williams, like many other authors examining police in the class system, agrees that the new police in England were formed as a result of the government and the upper class fearing a loss of control. Those in power at the time had realized their inadequacy in influencing older versions of law enforcement and therefore required an overhaul of the old system. These new police, in Williams's opinion, were primarily formed to execute control over the public space. In other words, as an extension of the upper class without the need for direct contact with those they wished to control.

Another vital aspect of William's view of police within the control systems of London refers to the technological advancements taking place at the time the London Metropolitan Police were founded. He states that there is a direct link between communication and control and that 
the emergence of methods like meticulous record keeping and the establishment of systems like punch cards were used to maintain regulation within a larger force. It was then possible for a few members of the upper class within the government to maintain authority over the working police. According to Williams's theory, it would have been much easier to maintain the highest level of order, over the largest group of people, maintained by the smallest number of overseers in this structure.

\section{Conclusion}

In conclusion, researchers studying the relation of class structure to policing in the early $19^{\text {th }}$ century circle two basic ways in which they interact: conflict perspective, or class as a reason for the development of the police, and consensus perspective, or class as a means by which the police developed. Many authors in this field touch on both theories, and although there is often a clear preference or line of thinking, both perspectives are practically unavoidable. It is also explicitly clear that the class structure of the United Kingdom steered the way the new police developed.

Just as there is not much argument that both theories played a role in the establishment of the modern police force, there is no argument rejecting the concept that, once established, the police were used by the government and the upper classes as a tool of social control. There is simply a divide in the discourse when it comes to the underlying reasons the establishment of such a system of law enforcement was first established. It is undeniable, at this stage, that many factors were influencing the development of modern law enforcement in London during the 1800 's. Influence of the existing class system, public attitudes, and belief in the importance of a comprehensive method of social control together led to the creation of the London Metropolitan Police. 


\section{Possibilities for Further Research}

It is clear based on these findings that the role of class in the establishment of the modern police force is an area of study that requires more attention than I have given it. It would be beneficial to take a closer look at the discourse surrounding the conflict and consensus perspectives. Although these sociological theories are often mentioned within the discourse, even if not by name, there is some dissent as to whether these theories are suited to the material. Conflict perspective, for example, has been accused of limiting perspectives and of providing an altogether useless conceptualization (Robert E. Wood, 1983). I believe it would also be useful to examine these theories in respect to the current state of international policing. It is not unreasonable to assume that worldwide class systems are at work which influence the autonomy and dynamics of our international law enforcement (Deflem, 2000). Finally, sociology as an interdisciplinary field should be applied more thoroughly when examining the field of policing, as, historically, many aspects of this association have been underdeveloped (Deflem, 2000; Jones, 1983; Robinson and Scaglion 1987; Williams, 2014) 


\section{Bibliography}

- Beattie, J.M. (2007), Sir John Fielding and Public Justice: The Bow Street Magistrates' Court, 1754-1780, Law and History Review Vol. 25, pp. 61-100, Retrieved from http://www.jstor.org.proxy.lib.pdx.edu/stable/pdf/27641430.pdf?refreqid=search\%3A058 6ceccc5b360e7ff7adeb881a04c21

- Broeker, Galen, (1961) Robert Peel and the Peace Preservation Force, The Journal of Modern History, Vol. 33, No. 4, pp. 363 to 373, Retrieved from http://www.jstor.org.proxy.lib.pdx.edu/stable/pdf/1877213.pdf?refreqid=search\%3Acf9c 98cc1c4dcf6caaeba8eddcbb7c73

- Clark, Gregory (2005). The Condition of the Working Class in England, 1209-2004. Journal of Political Economy, 113(6), 1307 -1340. doi:10.1086/498123. Retrieved from: http://www.jstor.org.proxy.lib.pdx.edu/stable/pdf/10.1086/498123.pdf

- Deflem, Matheiu (2000). Bureaucratization and Social Control: Historical Foundations of International Police Cooperation, Law \& Society Review, Vol. 34, No. 3 pp. 739-778. Retrieved from: http://www.jstor.org.proxy.lib.pdx.edu/stable/pdf/3115142.pdf

- Dickson, A., \& Speirs, W. (1980). Changes in Class Structure in Paisley, 1750-1845. The Scottish Historical Review, 59(167), 54-72. Retrieved from http://www.jstor.org.proxy.lib.pdx.edu/stable/25529357

- Dixon, A. (1929). The English Police System. The Annals of the American Academy of Political and Social Science, 146, 177-192. Retrieved from http://www.jstor.org.proxy.lib.pdx.edu/stable/1017560

- Durkheim, Emile. (1893) The Division of Labor in Society. Trans. W. D. Halls, intro. Lewis A. Coser. New York: Free Press, (1997). Print

- Glaeser, Edward L. and Sacerdote, Bruce (1999) Why Is There More Crime In Cities? Journal of Political Economy, Vol. 107, No. S6, pp. S225-S258 Retrieved from: http://www.jstor.org.proxy.lib.pdx.edu/stable/pdf/10.1086/250109.pdf

- Jones, D.J.V. (1983). The New Police, Crime and People in England and Wales, 18291888. Transactions of the Royal Historical Society, 33, 151-168. doi:10.2307/3678994 Retrieved from http://www.jstor.org.proxy.lib.pdx.edu/stable/pdf/3678994.pdf

- Joshi, Rajesh, (2000) Democratising the Police: Lessons from UK, Economic and Political Weekly, Vol. 35, No. 40 (Sep. 30 - Oct. 6, 2000), pp. 3589- 3596, Retrieved from: http://www.jstor.org.proxy.lib.pdx.edu/stable/pdf/4409808.pdf?refreqid=search\%3A99b1 $\mathrm{d} 3930160 \mathrm{ae} 03 \mathrm{c} 8 \mathrm{e} 552 \mathrm{e} 9 \mathrm{f} 5 \mathrm{~d} 1624 \mathrm{c}$

- Kraus, M., Piff, P., \& Keltner, D. (2011). Social Class as Culture: The Convergence of Resources and Rank in the Social Realm. Current Directions in Psychological Science, 20(4), 246-250. Retrieved from http://www.jstor.org.proxy.lib.pdx.edu/stable/23045780

- Liska, Alan E. (1987) A Critical Examination of Macro Perspectives on Crime Control, Annual Review of Sociology, Vol. 13 (1987), pp.67to 88. Retrieved from: http://www.jstor.org.proxy.lib.pdx.edu/stable/pdf/2083240.pdfrefreqid=search:8766f9d18 $\underline{\text { 8d19dd8d277543188afa925 }}$

- Lyman, J. (1964). The Metropolitan Police Act of 1829: An Analysis of Certain Events Influencing the Passage and Character of the Metropolitan Police Act in England. The Journal of Criminal Law, Criminology, and Police Science, 55(1), 141-154. doi:10.2307/1140471 Retrieved from: http://www.jstor.org.proxy.lib.pdx.edu/stable/pdf/1140471.pdf

- Marx, Karl and Engels, Friedrich (1848) The Communist Manifesto International Publishers Co, New York (2014). Print. 
- Neale, R. S. (1968). Class and Class-Consciousness in Early Nineteenth-Century England: Three Classes or Five? Victorian Studies, 12(1), 5-32. Retrieved from http://www.jstor.org.proxy.lib.pdx.edu/stable/3826429

- Reiner, R. (1978). The Police in the Class Structure. British Journal of Law and Society, 5(2), 166-184. doi:10.2307/1409625.

- Reiner, R. (1992). Police Research in the United Kingdom: A Critical Review. Crime and Justice, 15, 435 to 508. Retrieved from: http://www.jstor.org.proxy.lib.pdx.edu/stable/1147623

- Robinson, C., \& Scaglion, R. (1987). The Origin and Evolution of the Police Function in Society: Notes toward a Theory. Law \& Society Review, 21(1), 109-153. doi: $10.2307 / 3053387$. Retrieved from: http://www.jstor.org.proxy.lib.pdx.edu/stable/pdf/3053387.pdf

- Thorstein Veblen, (1899), The Theory of the Leisure Class: An Economic Study of Institutions, Dover Thrift Edition Published May 20, 1994. Print.

- Williams, Chris A., (2014) Police Control Systems In Britain, Manchester University Press, 2014. Ebook.

- Wood, Robert E. (1983). Conflict Theory as Pedagogy: A Critique from the Left, Teaching Sociology, Vol. 10, No. 4 pp. 463-485. Retrieved from: http://www.jstor.org.proxy.lib.pdx.edu/stable/pdf/1317296.pdf 